DOI 10.36622/VSTU.2021.51.3.005

UDC 621.642 .02

\author{
N. N. Osipova ${ }^{1}$, B. M. Grishin ${ }^{2}$
}

\title{
MODELING OF OPERATING MODES GAS COMPOSITE CYLINDERS
}

\author{
Saratov State Technical University Named after Gagarin Yu. A., \\ Institute of Urban Planning, Architecture and Construction ${ }^{1}$ \\ Russia, Saratov \\ Penza State University of Architecture and Construction, \\ Institute of Engineering Ecology ${ }^{2}$ \\ Russia, Penza
}
${ }^{1}$ D. Sc. in Engineering, Head of the Dept. of Heat and Gas Supply and Oil and Gas, tel.: (8452) 99-88-93, e-mail: osnat75@mail.ru
${ }^{2}$ D. Sc. in Engineering, Head of the Dept. of Water Supply, Sewerage and Hydraulic Engineering, tel.: (8412) 92-95-08

Statement of the problem. The emergence of composite cylinders on the market offers a range of technological and operational advantages in comparison with metal cylinders of liquefied hydrocarbon gas. At the same time, the absence of substantiated recommendations for determining the vapor capacity of cylinders by modes of their operation in the scientific literature limits their wide implementation into gas practice.

Results. A mathematical model considering the operation of the cylinder in the mode of periodic gas consumption is developed, the coefficient of non-uniformity of gas consumption during the day is calculated, the values of the heat transfer coefficient of the composite cylinder wall are identified, the approximate dependence of the heat transfer coefficient is obtained.

Conclusions. As a result of the research, the criteria influencing steam productivity of composite cylinders of the liquefied hydrocarbon gas in various operating modes are found.

Keywords: composite cylinder, liquefied hydrocarbon gas, periodic gas consumption, steam capacity, heat transfer coefficient.

Introduction. Temporary and periodic (seasonal) gas supply to facilities located remotely from natural gas mains are largely supplied using liquefied petroleum gas (LPG) cylinders while ensuring the use of gas for cooking and hot water preparation $[1,5,11]$.

The most common metal gas cylinders with a volume of 5 to 50 liters $[9,18]$ are the most common. However, these cylinders have considerable disadvantages:

- susceptibility to corrosion;

- explosion hazard;

(C) Osipova N. N., Grishin B. M., 2021 
- significant weight of an empty cylinder;

- impossibility to control the level of gas in the cylinder due to its opacity.

Composite cylinders are free from these disadvantages as they are easy to store, carry, transport. They have a greater aesthetics and come in a wide range of sizes and shapes. The market for composite cylinders is dominated by manufacturers Rugasco (Russia), Heagon Ragasco (Norway), Armotech, HPC Research (Czech Republic), Life Safe, Supreme (India) [10].

At the same time, the use of composite cylinders in the household sector requires practical guidelines for identifying the steam capacity of tanks and operating conditions. The available recommendations for metal cylinders in this case are not applicable, and there are no scientific studies to have identified the steam capacity of composite cylinders in the known literature.

The goal of the study is to identify the criteria that affect the steam production of composite cylinders of liquefied hydrocarbon gas under conditions of natural convection of internal air in the room considering the periodic gas consumption and changes in the filling level of the cylinder with the liquid phase of the gas.

1. Development of a mathematical model of periodic gas consumption. Studies $[3,4,6$, $12,16,22]$ show that the steam capacity of containers with gas operating under pressure is identified by a number of technical characteristics with the following major ones:

- component composition of gas;

- ambient temperature;

- minimum filling level of the container;

- duration of gas consumption, etc.

With constant extraction of the vapor phase from the cylinder during the day, the calculated steam capacity of the cylinder under the worst operating conditions, $\mathrm{kg} / \mathrm{h}$, is given by the formula $[4,15]$ :

$$
g=\frac{k \cdot F_{c M}^{\min }\left(t_{s}-t_{\varkappa c}^{\min }\right)}{r}
$$

where $k$ is the coefficient of the heat transfer of the cylinder wall, $\mathrm{kJ} \cdot \mathrm{h} / \mathrm{m}^{2} \mathrm{~K} ; F_{c m}^{\min }$ is the wetted surface of the cylinder of the liquid gas phase corresponding to the minimum level of its filling, $\mathrm{m}^{2} ; t_{B}$ is the temperature of the environment, ${ }^{0} \mathrm{C} ; t_{\varkappa}^{\min }$ is the minimum temperature of the liquefied gas in the cylinder before another filling, ${ }^{0} \mathrm{C} ; r$ is the hidden vaporization heat of the liquefied gas, $\mathrm{kJ} / \mathrm{h}$.

Under actual operating conditions of cylinders, gas consumption is commonly of a periodic nature, while the periods of evaporation of the liquid phase "I" are changed by the periods of 
rest "O". During the rest period, there is an increase in the temperature of the liquid phase of the gas due to heat exchange with the environment and that in the equilibrium vapor pressure $[17,21]$. The heat balance of the specified period can be described by the expression:

$$
k F_{c m}^{O}\left(t_{в}-t_{\varkappa}\right) d \tau=\left(c_{2} M_{2}^{O}+c_{c m} M_{c m}^{O}\right) d t+r d G,
$$

where $F_{c M}^{O}$ is the wetted surface of the cylinder corresponding to the rest mode, $\mathrm{m}^{2} ; t_{\rightsquigarrow}$ is the temperature of the liquefied gas, ${ }^{0} \mathrm{C}$; $d \tau$ is change of the time when the rest of the cylinder is examined, $\mathrm{h} ; c_{2}, c_{c m}$ is the heat capacity of the liquefied gas and cylinder walls respectively, $\mathrm{kJ} / \mathrm{kg} \cdot \mathrm{K} ; M_{2}^{O}, M_{c m}^{O}$ is the mass of the liquid phase of the gas in the cylinder in the rest period and cylinder body contacting with the liquid phase, $\mathrm{kg}$; $d t$ is change of the temperature over the rest period of the cylinder, ${ }^{0} \mathrm{C} ; G$ is the mass of the vapour phase in the cylinder, $\mathrm{kg}$.

Assuming that the change in the mass of the liquid and the area of the wetted surface during a separate period of vapor consumption occurs insignificantly, let us assume:

$$
\begin{aligned}
F_{c M}^{O} \cong F_{c M}^{U} ; \\
M_{2}^{O} \cong M_{2}^{h} ; \\
M_{c m}^{O} \cong M_{c m}^{h} .
\end{aligned}
$$

Then the expression (2) can be presented as follows:

$$
k F_{c M}^{U}\left(t_{B}-t_{\varkappa}\right) d \tau=\left(c_{2} M_{2}^{U}+c_{c m} M_{c m}^{U}\right) d t+r d G .
$$

An increase in the equilibrium vapor pressure due to additional evaporation of LPG is a second-order value $r d G \rightarrow 0$ and may not be taken into consideration in further studies. In this case, the calculation error does not exceed $2 \%$.

Then the duration of the rest period of the cylinder is given by the expression:

$$
d \tau=\frac{c_{2} M_{2}^{U}+c_{c m} M_{c m}^{U}}{k F_{c m}^{U}} \cdot \frac{d t}{t_{B}-t} .
$$

The cylinder is heated during the rest process, which takes place in the time interval from 0 to $\tau_{\kappa о н}$, while the gas temperature in the cylinder changes from $t_{И}$ to $t_{O}$ :

$$
\int_{0}^{\tau_{\text {коH }}} d \tau=\frac{c_{2} M_{2}^{H}+c_{c m} M_{c m}^{U}}{k F_{c M}^{U}} \int_{t_{U}}^{t_{O}} \frac{d t}{t_{B}-t} .
$$

Then, integrating the expression in the above ranges of parameter variation, we get:

$$
\tau_{\text {кон }}=\frac{c_{2} M_{2}^{U}+c_{c m} M_{c m}^{U}}{k F_{c M}^{U}} \ln \frac{t_{s}-t_{U}}{t_{B}-t_{O}} .
$$


Let us express the temperature of the liquefied gas at the end of the rest period:

$$
t_{O}=t_{B}-\frac{t_{B}-t_{U}}{e^{\frac{k F_{c m}^{H} \tau_{o n}}{c_{2} M_{2}^{U}+c_{c m} M_{c m}^{U}}}},
$$

where $e$ is the Euler's number.

Intensive vaporization of gas in the cylinder takes place in the process of gas consumption, while the vapor phase is formed partly due to the influx of heat from the environment and a decrease in the temperature of the gas in the cylinder. At the same time, there is a drop in the equilibrium elasticity of saturated vapors.

The heat balance equation of the cylinder during the gas consumption period has the form:

$$
k\left(\frac{F_{c m}^{O}+F_{c m}^{U}}{2}\right)\left(t_{b}-t\right)+\left(c_{2}\left(\frac{M_{2}^{O}+M_{2}^{U}}{2}\right)+c_{c m}\left(\frac{M_{c m}^{O}+M_{c m}^{U}}{2}\right)\right) d t=r g d \tau .
$$

Given the assumption (2), the expression (9) takes the form:

$$
k F_{c m}^{U}\left(t_{b}-t\right) d \tau+\left(c_{\Gamma} M_{2}^{u}+c_{c m} M_{c m}^{u}\right) d t=r g d \tau .
$$

The duration of the vaporization period is defined as

$$
d \tau=\frac{\left(c_{c} M_{2}^{U}+c_{c m} M_{c m}^{U}\right) d t}{r g-k F_{c M}^{U}\left(t_{b}-t\right)} .
$$

The duration of gas evaporation in the cylinder taking into consideration the range of values of the change in time $0 \leq d \tau \leq \tau_{u c n}$ :

$$
\int_{0}^{\tau_{u c n}} d \tau=\int_{t_{U}}^{t_{0}} \frac{\left(c_{2} M_{2}^{H}+c_{c m} M_{c m}^{U}\right) d t}{r g-k F_{c M}^{U}\left(t_{B}-t\right)} .
$$

After inserting the limits, we get

$$
\tau_{u c n}=\frac{\left(c_{2} M_{2}^{U}+c_{c m} M_{c m}^{U}\right)}{k F_{c M}^{U}} \ln \frac{r g-k F_{c M}^{U}\left(t_{s}-t_{O}\right)}{r g-k F_{c M}^{U}\left(t_{s}-t_{И}\right)} .
$$

Let us transform expression (13) taking into consideration expression (8) identifying the hourly gas consumption by the cylinder:

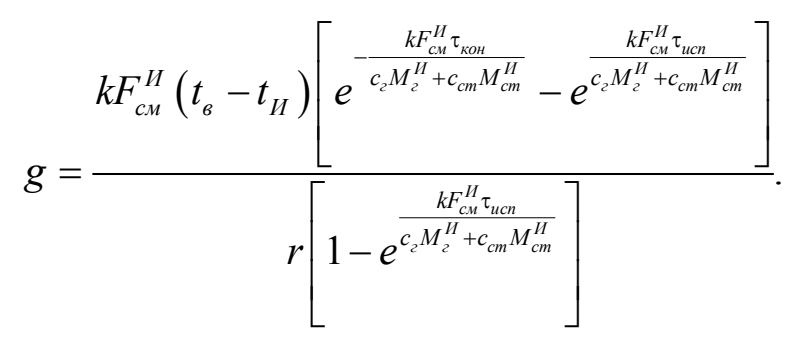

The analysis of expressions (1) and (14) shows that the steam capacity of the cylinder with periodic extraction of vapors should be adjusted considering the presence of periods of gas 
evaporation and rest. The correction factor for uneven gas consumption in this case can be presented as the ratio of the total period of use of the cylinder to the period of vaporization of gas in the cylinder:

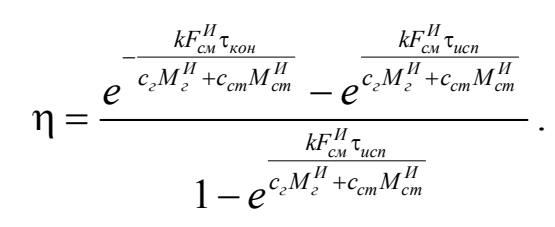

According to the analysis of expression (15), the correction factor $\eta$ exists in the range of values:

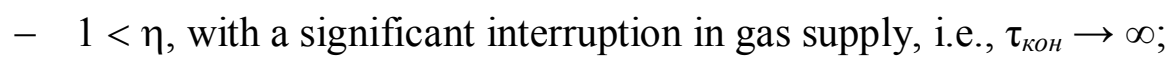

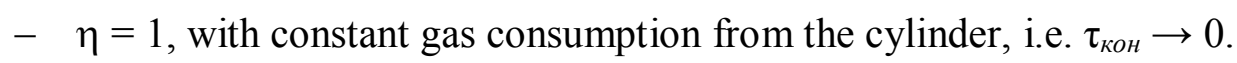

Then expression (1) in conditions of periodic consumption of gas from the cylinder will take the form:

$$
g=\frac{k F_{c u}\left(t_{s}-t_{\varkappa}\right) \eta}{r}
$$

2. Identifying the heat transfer coefficient of the wall of the composite cylinder. In order to be able to implement expression (16), it is necessary to perform research to identify the values of the heat transfer coefficient of the wall of the composite cylinder. A large number of studies are devoted to the study of the process of heat transfer through the metal wall of cylinders and LPG tanks $[2,3,7,13,23]$. At the same time, there is no information in the known literature on the features of heat transfer through the wall of a composite balloon. A considerable difference in the material of manufacture does not enable the use of the values of the heat transfer coefficients used in the calculation of metal pressure vessels and identifying the amount of heat transfer from the environment to the composite cylinder according to the known dependencies with no appropriate adaptation.

Let us consider the flow of heat to the liquid phase of liquefied gas (Fig. 1).

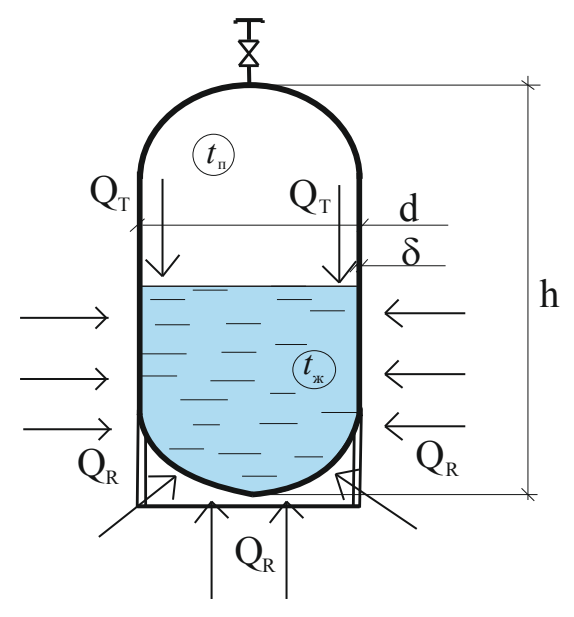

Fig. 1. Calculation scheme cylinder heat exchange tasks with the environment 
The impact of the environment on the cylinder is performed in two characteristic zones:

- washed gas liquid phase (radial heat);

- washed vapor phase of the gas and the liquid phase transferred along the wall (tangential heat).

In order to address the problem, the following assumptions will be used:

- heat supply to the cylinder from air is carried out due to natural convective heat transfer $[14,19,20]$;

- the temperature of the cylinder wall is the same in thickness and constant: $t_{c m}=$ const;

- the temperature of the wall washed by the liquid phase is equal to that of the liquefied gas: $t_{c m}=t_{\rightsquigarrow}[6]$.

The amount of heat supplied to the liquid due to the radial conductivity of the cylinder wall is

$$
Q_{R}=\alpha\left(t_{B}-t_{\varkappa}\right) F_{c M},
$$

where $\alpha$ is the the coefficient of heat transfer from the environment to the wall of the composite cylinder, Watt $/ \mathrm{m}^{2} \mathrm{~K}$.

In turn, the area of the wetted surface of the cylinder, $\mathrm{m}^{2}$, is defined as

$$
F_{c M}=\pi h \varphi(d-2 \delta)+\frac{\pi(d-2 \delta)^{2}}{4}
$$

where $h$ is the height of the composite LPG cylinder, $\mathrm{m}$; $d$ is the cylinder diameter, $\mathrm{m}$; $\delta$ is the wall thickness of the composite cylinder, $\mathrm{m} ; \varphi$ is the level of filling the balloon with the liquid phase, proportions.

The heat gain to the liquid phase of the product due to the tangential conductivity of the cylinder wall will thereby have the following form:

$$
Q_{t}=\lambda_{c m} P_{t}\left(t_{s}-t_{\varkappa}\right),
$$

where $\lambda_{c m}$ is the thermal conductivity coefficient of the cylinder wall participating in tangential heat transfer, Watt $/ \mathrm{m} \cdot \mathrm{K} ; P_{t}$ is the perimeter of the surface of the cylinder walls participating in tangential heat transfer, $m$.

The perimeter of the cylinder surface participating in heat exchange with the vapor phase and transferring heat tangentially is given by the formula:

$$
P_{t}=2 \pi h(d-2 \delta)(1-\varphi) .
$$

The total amount of heat inflow to the liquid phase of LPG in the cylinder will be defined as

$$
Q=Q_{R}+Q_{t}
$$


Therefore the heat transfer coefficient of the wall of the composite cylinder, referred to its wetted surface, coonsidering expressions (17)—(20), will take the form:

$$
k=\alpha+\frac{\lambda_{c m} P_{t}}{F_{c M}} .
$$

Given that the cylinders is installed in the kitchen, in the immediate proximity to the gas stove, the heat transfer from the air to the wall of the composite cylinder will occur due to the natural convection of the air in the room. The heat transfer coefficient from air of a smooth non-metallic surface in this case is given by the ratio [19, 20]:

$$
\alpha=f(v),
$$

where $v$ is the air velocity near the surface, $\mathrm{m} / \mathrm{sec}$.

Considering the regulatory requirements for the velocity of air movement in the premises of kitchens of residential buildings in compliance with SanPiN (СанПиН) 2.1.2645, the value of the heat transfer coefficient will take the value of $6.6 \mathrm{Watt} / \mathrm{m}^{2} \mathrm{~K}$.

According to expression (22), given (18), (20), (23), calculations were performed to identify the heat transfer coefficient of the wall of a composite LPG cylinder of the two most common standard sizes of cylinders with a volume of 24.5 and 47 liters considering the dynamics of changes in the level of filling with the liquid phase of the gas in the range of $10 \% \leq \varphi \leq 85 \%$. The calculation results are shown in the graphs (Fig. 2). To compare, Fig. 2 presents the results of research [8] to identify the heat transfer coefficient of steel 50-liter LPG cylinders.

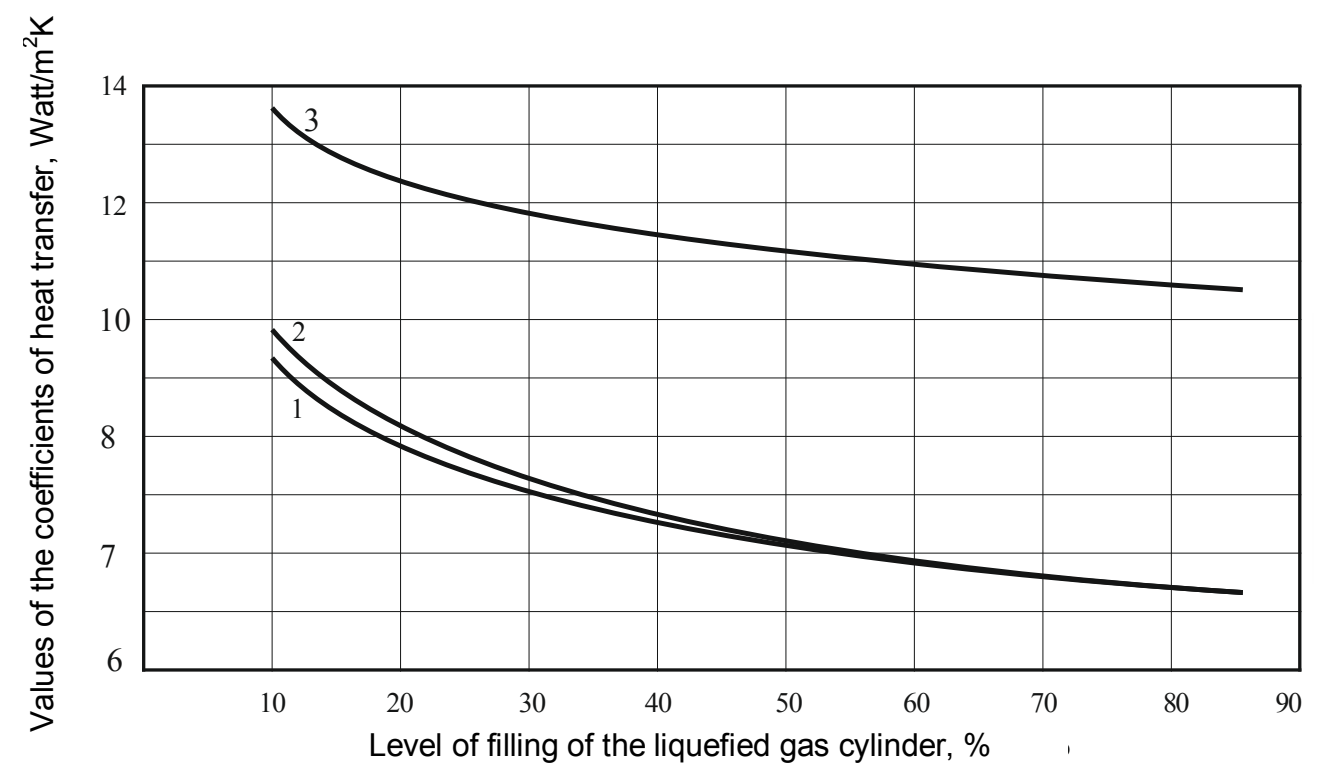

Fig. 2. Values of the heat transfer coefficient of the wall of LPG cylinders:

1 - composite cylinder with a volume of 24.5 liters; 2 - a composite cylinder with a volume of 47 liters; 3 - metal cylinder with a volume of 50 liters 
According to the analysis of the graphs (Fig. 2), the heat transfer coefficient of the cylinder wall depends considerably on the filling level. The smallest values of the coefficient of 6.7 Watt $/ \mathrm{m}^{2} \mathrm{~K}$ are observed at a liquid phase level in the cylinder of $85 \%$. As the cylinder is emptied, the heat transfer coefficient increases and at the minimum filling level $(10 \%)$ is 9.8 Watt $/ \mathrm{m}^{2} \mathrm{~K}$ for a composite cylinder with a volume of 47 liters and $9.4 \mathrm{~W} / \mathrm{m}^{2} \mathrm{~K}$ for a composite cylinder with a volume of 24.5 liters, respectively.

The comparison of the heat transfer coefficients of the metal wall and the wall of the composite cylinder shows a significant discrepancy between the values. The largest difference is $53.7 \%$ with an initial fill level of $85 \%$.

Hence the material of manufacture of cylinders has a considerable impact on the value of the heat transfer coefficient. Thus the use of the main dependencies for identifying the heat flow for metal cylinders and the formation of recommendations for identifying the steam capacity of composite cylinders will lead to a significant error in determining the operating parameters. Computer processing of the research results made it possible to obtain an expression for identifying the heat transfer coefficient of the wall of a composite cylinder considering its level of filling with the liquid phase of the gas. The expression is valid for a range of fill level values from $10 \% \leq \varphi \leq 85 \%$ with a correlation of $\mathrm{R}^{2}=0.997$ :

$$
k=-0.1 \cdot 10^{-5} \varphi^{3}+0.25 \cdot 10^{-2} \varphi^{2}-0.17 \varphi+10.96 .
$$

3. Identifying the coefficient of unevenness of gas consumption. In order to identify the correction factor $\eta$ in expression (16), the corresponding calculations were performed. The following were taken as the initial data:

- variable continuous duration of gas consumption per day - 1, 2, 4, 8, 12, 16, 24 hours;

- filling the cylinder with the liquid gas phase - 50 and $10 \%$;

- the volume of composite cylinders - 24.5 and 47 liters.

The calculation results are presented in Fig. 3.

According to the calculation, the coefficient of unevenness of gas consumption takes on values of more than one if gas consumption is conducted for less than four hours a day. In this case, an increase in the steam capacity of the cylinder will be essential. E.g., with a gas consumption duration of one hour, the coefficient $\eta=2$ (with a cylinder volume of 47 liters and a liquid phase filling level of $50 \%$, curve 1), this means that the amount of vaporized gas in the cylinder doubles. A similar situation is observed when using a cylinder with a smaller capacity. With a cylinder volume of 24.5 liters and an hourly continuous gas consumption, the gas consumption unevenness coefficient is 1.5 (curve 2). With a drop in the filling of the cylin- 
ders with gas, the values of the coefficient drop as well and range from 1.2 (24.5 1 cylinder, curve 4) to 1.4 (50 1 cylinder, curve 3 ). At the same time, the difference in the values of the coefficient depending on the volume of the cylinder and the level of its filling with the liquid phase is observed only during the period of gas consumption up to four hours. So, e.g., with a gas consumption duration of 2 hours for a 47 liter cylinder with a liquid phase filling level of $50 \%$, the coefficient has a value of $\eta=1.4$, and with a liquid phase filling level of $10 \%$ $\eta=1.1$, i.e., it differs by 21 , five $\%$. When the duration of gas consumption is reduced to 1 hour, the difference in values goes up to $30 \%$.

Hence with the continuous use of cylinders for less than four hours, it is necessary to take into consideration the coefficient of unevenness of gas consumption, which ensures an increase in their steam production.

With a gas consumption duration of more than four hours, the gas consumption unevenness coefficient becomes equal to unity, and it can be assumed that the cylinder operates in the mode of continuous extraction of the vapor phase of the gas at any volume of the gas cylinder and any level of filling with the liquid phase of the gas.

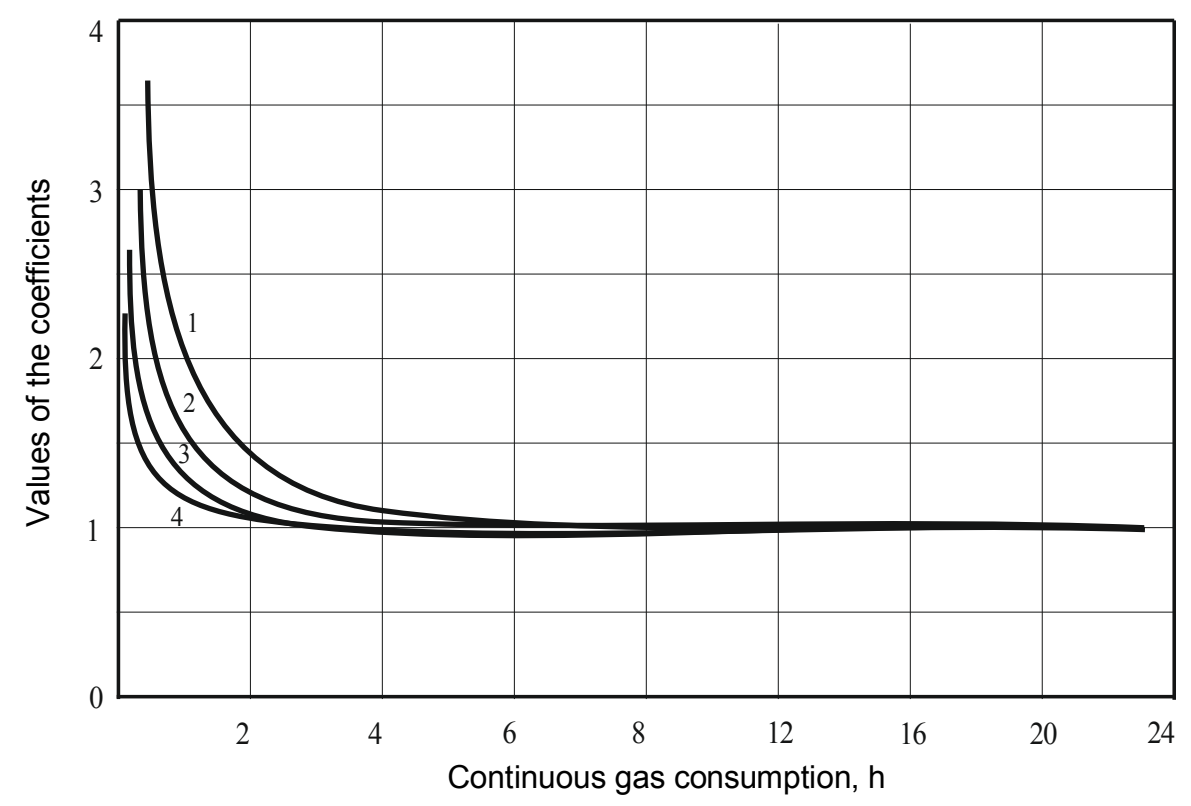

Fig. 3. Coefficient values $\eta$ depending on the duration of continuous gas consumption during the day:

1 - cylinder with a volume of 47 liters, filling level - 50\%; 2 - balloon with a volume of 24.5 liters, filling level $-50 \% ; 3$ - balloon with a volume of 47 liters, filling level $-10 \%$;

4 - balloon with a volume of 24.5 liters, filling level - $10 \%$ 
Conclusions. The practical significance of the study is the development of a mathematical model of heat exchange of a composite cylinder with the environment in a periodic mode of gas consumption, the establishment of criteria impacting the steam capacity of the cylinder under conditions of natural convection of ambient air considering the tangential conductivity of the wall in contact with the vapor phase of liquefied gas, obtaining an approximating dependence for identification of the heat transfer coefficient of the cylinder wall depending on the filling level of the cylinder with gas, the correction factor to the design capacity of the cylinder in conditions of periodic gas consumption.

The scientific substantiation of the new results provided in the article will make enable recommendations to be developed for choosing operating modes for composite cylinders of liquefied gas, which will increase their attractiveness in the gas supply market for periodically and seasonally operated facilities.

\section{References}

1. Ionin A. A., Zhila V. A., Artikhovich V. V., Pshonik M. G. Gazosnabzhenie [Gas supply]. Moscow, ASV Publ., 2012. 472 p.

2. Kuritsyn B. N., Ivanova E. V., Pavlutin M. V. Obosnovanie komponentnogo sostava szhizhennogo gaza dlya kommunal'no-bytovogo potrebleniya [Substantiation of the component composition of liquefied gas for municipal consumption]. Vestnik BGTU im. V. G. Shukhova, 2003, no. 6, pp. 54-57.

3. Kuritsyn B. N., Osipova N. N., Maksimov S. A. [Temperature regimes of storage of liquefied petroleum gas in underground tank installations]. Materialy XI Mezhdunar. nauch.-prakt. konf. «Problemy energosberezheniya i ekologii v promyshlennom i zhilishchno-kommunal'nom kompleksakh» [Proc. "Problems of energy saving and ecology in industrial and housing and communal complexes"]. Penza, Privolzhskii Dom znanii publ., 2010, pp. 166-169.

4. Kuritsyn B. N., Osipova N. N., Usachev A. P., Maksimov S. A. Issledovanie teploobmena pri khranenii i regazifikatsii szhizhennogo uglevodorodnogo gaza v podzemnykh rezervuarnykh ustanovkakh [Investigation of heat exchange during storage and regasification of liquefied petroleum gas in underground tank installations]. Vestnik grazhdanskikh inzhenerov, 2011, no. 3 (28), pp. 82-87.

5. Kuritsyn B. N., Postarnak D. A., Bessonova N. S. [Reduction of material and energy intensity of settlement systems of gas distribution and gas consumption]. Materialy Mezhdunar. nauchn.-prakt. konf. «Resursoenergoeffektivnye tekhnologii v stroitel'nom komplekse regiona» [Proc. "Resource-and energy-efficient technologies in the construction complex of the region"]. Saratov, SGTU Publ., 2013, pp. 353-355.

6. Kuritsyn B. N., Postarnak D. A. [Modeling of heat exchange in installations of balloon supply with liquefied gas]. Materialy Mezhdunar. nauchn.-prakt. konf. «Kul'turno-istoricheskoe nasledie stroitel'stva: vchera, segodnya, zavtra» ["Cultural and historical heritage of construction: yesterday, today, tomorrow"]. Saratov, SGAU Proc., 2014, pp. 69-72. 
7. Osipova N. N., Grishin B. M., Greisukh G. I., Ezhov E. G. Rezhimy ekspluatatsii sistem gazosnabzheniya na baze ballonnykh ustanovok szhizhennogo uglevodorodnogo gaza [Modes of operation of gas supply systems based on cylinder installations of liquefied petroleum gas]. Regional'naya arkhitektura i stroitel'stvo, 2018, no. 3 (36), pp. $184-193$.

8. Postarnak D. A., Kuritsyn B. N. [The use of butane-ethane mixtures in balloon gas supply systems]. Materialy XXVI Mezhdunar. nauch. konf. «Matematicheskie metody v tekhnike i tekhnologiyakh — MMTT» [Materials of the XXVI International Scientific Conference "Mathematical methods in engineering and technologiesMMTT"]. Saratov, SGTU Publ., 2013, pp. 220-222.

9. Rynok szhizhennykh uglevodorodnykh gazov. Tekushchaya situatsiya i prognoz 2014-2018 gg.: marketingovoe issledovanie [The market of liquefied petroleum gases. Current situation and forecast 2014-2018: marketing research]. ALTO CONSULTING GROUP, 2014. 167 p.

10. Tul'tsov V. A. Primenenie kompozitnykh gazovykh ballonov pri gazosnabzhenii potrebitelei [The use of composite gas cylinders for gas supply to consumers]. Sovershenstvovanie metodov gidravlicheskikh raschetov vodopropusknykh i ochistnykh sooruzhenii, 2019, vol. 1, no. 1 (44), pp. 115-118.

11. Argus Argus International LPG: daily international LPG prices and market commentary, Argus Media Group, Issue 18-22, January 2018. Available at: https:/www.argusmedia.com/-/media/Files/sample-reports/argusinternational-lpg.ashx?la=en\&hash=1083A42166DD26A422034E980B71BD33993755B9.

12. Chen Q. S., Wegrzyn J., Prasad V. Analysis of temperature and pressure changes in liquefied natural gas (LNG) cryogenic tanks. Cryogenics, 2004, no. 44 (10), pp. 701-709. Available at: https://citeseerx.ist.psu.edu/viewdoc/download?doi=10.1.1.652.462\&rep=rep1\&type=pdf.

13. Cristescu T., Ciobanu P. On a Class of Thermodynamic Process Involved in the Transport and Storage of Liquefied Petroleum Gas. Oil \&Gas University of Ploiesti Bulletin. Technical Series, 2010, vol. 62, no. 3B, pp. $162-168$.

14. Jha B. K., Oni M. O. Transient natural convection flow between vertical concentric cylinders heated/cooled asymmetrically. Proc IMechE, Part A: J Power Energy, 2018, no. 232, pp. 926—939.

15. Jones J. C. Hydrocarbons — Physical Properties and their Relevance to Utilisation Hydrocarbons Physical Properties and their Relevance to Utilisation. Ventus Publishing ApS, 2010.

16. Miana M., Del Hoyo R., Rodrigalvarez V. Comparison of evaporation rate and heat flow models for prediction of liquefied natural gas (LNG) ageing during ship transportation. Fuel 2016:177:87-106. Available at: https://www.researchgate.net/publication/297597820_Comparison_of_evaporation_rate_and_heat_flow_models_for_prediction_of_Liquefied_Natural_Gas_LNG_ageing_during_ship_transportation.

17. Migliore C., Salehi1 A., Vesovic V. A non-equilibrium approach to modelling the weathering of stored / Liquefied Natural Gas (LNG). Calogero Migliore. Department of Earth Science and Engineering, Imperial College London, London SW7 2AZ, United Kingdom 2 Repsol, S. A., calle de Mendez Alvaro, 44, 28045, Madrid, Spain, 2019. 27 p.

18. Osipova N. N., Grishin B. M., Rodionov Yu. V., Tarakanov O. V., Greisukh G. I. Justification of operating conditions for gas supply systems based on cylinder units of liquefied hydrocarbon gas. J. of Engineering and Applied Sciences, 2016, vol. 11, no. 12, pp. 2723-2728.

19. Roh G. S., Son G. Numerical study of natural convection in a liquefied natural gas tank. J. Mech. Sci. Technol, 2012, vol. 26, pp. 3133-3144. 
20. Roh G. S., Son G., Song G. e. a. Numerical study of transient natural convection in a pressurized LNG storage tank. Appl. Therm. Eng, 2013, vol. 52, pp. 209-220.

21. Yaws C. L. The Yaws handbook of vapor pressure: antoine coefficients. Gulf Professional Publishing, New York, 2015.

22. Zakaria Z. B., Mustafa A., Mat H. Heat and mass transfer studies in liquefied petroleum gas storage operations. Universiti Teknologi Malaysia, 2006.

23. Zakaria Z. B., Mustafa A. The influence of compositions on liquefied petroleum gas residue in storage. Int. J. Recent. Res. Appl. Stud, 2011, vol. 7, pp. 360-367. 